\title{
Systemic inflammatory markers in COPD: results from the Bergen COPD Cohort
} Study

\author{
T.M.L. Eagan*,\#, T. Ueland",, , P.D. Wagner\#, J.A. Hardie*, T.E. Mollnes ${ }^{\S}$, \\ J.K. Damàs ${ }^{\tau, f, * \star}$, P. Aukrust ${ }^{\uparrow, f}$ and P.S. Bakke ${ }^{\star, \# \#}$
}

ABSTRACT: Chronic obstructive pulmonary disease (COPD) is considered an inflammatory pulmonary disorder with systemic inflammatory manifestations. The aim of this study was to assess the systemic levels of six inflammatory mediators in a large cohort of COPD patients and controls.

409 COPD patients and 231 healthy subjects, aged $40-75 \mathrm{yrs}$, were included from the first phase of the Bergen COPD Cohort Study. All COPD patients were clinically diagnosed by a physician, and had a forced expiratory volume in $1 \mathrm{~s} /$ forced vital capacity ratio less than 0.7 and a smoking history of $>10$ pack-yrs. The plasma levels of C-reactive protein (CRP), soluble tumour necrosis factor receptor (STNFR)-1, osteoprotegrin, neutrophil activating peptide-2, CXCL16 and monocyte chemoattractant protein-4 were determined by ELISA.

After adjustment for all known confounders, COPD patients had significantly lower levels of osteoprotegrin than subjects without COPD $(p<0.05)$, and higher levels of CRP $(p<0.01)$. Among COPD patients, CRP was elevated in patients with frequent exacerbations $(p<0.05)$. sTNFR-1 and osteoprotegrin were both related to Global Initiative for Chronic Obstructive Lung Disease stage and frequency of exacerbations in the last 12 months $(p<0.05)$. In addition, sTNFR-1 was significantly associated with important comorbidities such as hypertension and depression $(\mathbf{p}<0.05)$.

The present study confirms that certain circulating inflammatory mediators are an important phenotypic feature of COPD.

KEYWORDS: Chronic obstructive pulmonary osteoprotegrin, tumour necrosis factor receptor

hronic obstructive pulmonary disease (COPD) is a common inflammatory disease of the airways and the lung parenchyma, and its prevalence is increasing throughout the world. Several studies on COPD have demonstrated an influx of immune cells, both in the airway wall and lumen, the alveoli and pulmonary vessels [1]. Disease severity is associated with increased airways inflammation [2].

Several studies have shown that COPD patients have higher levels of some inflammatory markers in blood, notably C-reactive protein (CRP) [3-7], fibrinogen [8], and the inflammatory cytokines interleukin (IL)-6 [3, 6, 7, 9] and IL-8 [10, 11]. For tumour necrosis factor (TNF)- $\alpha$ the results are conflicting, as some studies $[9,12,13]$ have found higher TNF- $\alpha$ levels among COPD patients, whereas more recent studies have not $[3,7,10$, 14]. It has been suggested that systemic inflammation may explain part of the heterogeneity of disease, C-reactive protein, inflammation,

COPD phenotypes, such as loss of lean body mass [15], and the higher prevalence of comorbid disorders such as coronary heart disease (CHD), depression and hypertension [16, 17].

However, whether differences in inflammation are related to different phenotypes of COPD is as yet unclear. Most previously published studies on systemic inflammation in COPD have lacked a sample size that would allow for multivariable adjustment of many potential confounders. Of the studies examining TNF- $\alpha$ in COPD patients, the only study including $>100$ patients had 268 patients [7].

While several studies have focused on established inflammatory markers such as CRP, fibrinogen, TNF- $\alpha$, IL- 6 and IL- 8 , other markers of systemic inflammation could also be of interest due to their ability to reflect inflammatory pathways involved in the pathogenesis of COPD and

\section{AFFILIATIONS}

*Dept of Thoracic Medicine, Haukeland University Hospital, and \#\# Section of Pulmonary Medicine, Institute of Medicine, University of Bergen, Bergen,

"Research Institute for Internal Medicine,

${ }^{+}$Section of Endocrinology

§Institute of Immunology, and

${ }^{f}$ Section of Clinical Immunology and Infectious Diseases, Rikshospitalet

University Hospital, University of

Oslo, Oslo, and

${ }^{\star *}$ Dept of Infectious Diseases, St Olavs Hospital, Trondheim, Norway. \#Division of Physiology, University of California San Diego, La Jolla, CA, USA.

\section{CORRESPONDENCE}

T.M.L. Eagan

Dept of Thoracic Medicine Haukeland University Hospital 5021 Bergen

Norway;

E-mail: tomas.eagan@med.uib.no

Received:

June 042009

Accepted after revision: July 202009

First published online: July 302009 
associated comorbidities. While the plasma level of TNF- $\alpha$ is generally $<20 \mathrm{pg} \cdot \mathrm{mL}^{-1}$, soluble TNF receptors (sTNFR) circulate in higher levels (i.e. $>500 \mathrm{pg} \cdot \mathrm{mL}^{-1}$ ), being more stable and reliable markers of activity in the TNF- $\alpha$ system than plasma levels of TNF- $\alpha$ itself [18]. Moreover, chemokines are of major importance for the attraction and activation of leukocytes into inflamed tissue and could represent a systemic inflammatory link between COPD and associated comorbidities. However, while several chemokines circulate at very low levels just above the detection limit of the assay (e.g. IL- 8 generally circulates at $<10 \mathrm{pg} \cdot \mathrm{mL}^{-1}$ ), plasma levels of the chemokines neutrophil activating peptide (NAP)-2, CXCL16 and monocyte chemoattractant protein (MCP)-4 are much higher, being more reliable systemic markers of the activity in the chemokine network. Finally, certain members of the TNF superfamily (i.e. the RANKL/OPG/RANK system) play a major role in matrix degradation and inflammation. Osteoprotegrin (OPG) inhibits osteoclastogenesis by binding the receptor activator of nuclear factor- $\kappa \mathrm{B}$ ligand (RANKL), acting as a decoy receptor to competitively inhibit RANKL interaction with its receptor RANK (receptor activator of nuclear factor $-\kappa B$ ). OPG reflects the activity in the RANKL/OPG/RANK system, and could be an interesting systemic marker related to COPD phenotype. Accordingly, these five markers (sTNFR-1, NAP-2, CXCL16, MCP-4 and OPG), of which only sTNFR-1 has previously been examined in COPD patients, were analysed in a large cohort of COPD patients and individuals without COPD in the baseline phase of the Bergen COPD Cohort Study. For comparison, CRP was measured as a standard marker of upstream inflammatory activity.

\section{METHODS}

\section{Study population}

The study sample included 409 COPD patients and 231 subjects without COPD, aged 40-76 yrs, from the first phase of the Bergen COPD Cohort Study (fig. 1). The patients were recruited through outpatient clinics from several hospitals in Western Norway, and from three private specialist practices in Bergen (Norway). Three quarters of the patients lived within the geographical area of the Bergen hospital district, serviced by our own outpatient clinic at the Dept of Thoracic Medicine, Haukeland University Hospital (Bergen). The healthy subjects were among earlier participants of a large general population survey from the same area, the Hordaland County Cohort Study [19].

All invited subjects that wished to participate were examined by a study physician who performed a structured interview of the medical history including exacerbations, comorbidities, smoking and medication use. The following inflammatory disorders, either self-reported or from the available hospital journal, were cause for exclusion for both COPD patients and subjects without COPD: rheumatoid arthritis; systemic lupus erythematosus or other connective tissue disorders; inflammatory bowel disease; and any active cancer in the last 5 yrs. Common chronic comorbid disorders with known inflammatory components, such as CHD, hypertension and diabetes, were not cause for exclusion.

All COPD patients were examined by the study physician and reported as having a clinical diagnosis of COPD, with the added spirometric criteria of a forced expiratory volume in $1 \mathrm{~s}$
(FEV1)/forced vital capacity ratio post-bronchodilation of $<0.7$ and an FEV1 $<80 \%$ predicted based on Norwegian prebronchodilation reference values [20]. A smoking history of $\geqslant 10$ pack-yrs was required for inclusion for the COPD patients. Any exacerbation requiring medical treatment within the last 4 weeks led to postponement of the visit.

All participation was voluntary. Written information was provided and written consent was obtained prior to inclusion. The regional ethical committee (University of Bergen) approved the study.

\section{Data sampling}

The study physician obtained information on the exacerbation history for the last 12 months from the patient and the local hospital records if any were reported. All exacerbations that required medical treatment with antibiotics or oral steroids or hospitalisation were included. All participants were categorised as current, ex-, or never-smokers; 1 pack-yr was defined as 10 cigarettes per day per year. Arterial blood gases were taken by the physician, and arterial oxygen and carbon dioxide tensions and $\mathrm{pH}$ measured within 5 min were analysed on a Radiometer ABL 520 blood gas analyser (Radiometer, Copenhagen, Denmark). Hypoxaemia was defined as an arterial partial oxygen pressure of $<8.0 \mathrm{kPa}$. Patient care was provided as would have been provided at a regular outpatient visit.

Respiratory symptoms were obtained through a self-completed questionnaire used in previous studies [21, 22]. Trained study staff conducted spirometry, both pre- and post-inhalation of $0.4 \mathrm{mg}$ salbutamol, on a Viasys Masterscope (Viasys, Hoechberg, Germany). Spirometer calibration was performed with a 3-L calibration syringe twice daily. American Thoracic Society/European Respiratory Society reproducibility criteria for post-inhalation FEV1 [23] were met in 97\% of the measurements. After an overnight fasting, bioelectrical impedance measurements were performed with a Bodystat 1500 (Bodystat Ltd, Douglas, Isle of Man, UK). The fat free mass index (FFMI) was calculated as the fat free mass $(\mathrm{kg})$ divided by the square of height $\left(\mathrm{m}^{2}\right)$, and the fat mass index (FMI) was similarly calculated as the fat mass $(\mathrm{kg})$ divided by the square of height $\left(\mathrm{m}^{2}\right)$.

\section{Blood sampling protocol}

Peripheral venous blood was drawn into pyrogen-free blood collection tubes with ethylenediaminotetraacetic acid and centrifuged within $30 \mathrm{~min}$ at $2,150 \times g\left(15 \mathrm{~min}\right.$ at $\left.4^{\circ} \mathrm{C}\right)$. All samples were stored at $-80^{\circ} \mathrm{C}$ and thawed less than three times.

\section{Laboratory measurements}

The inflammatory markers were analysed by enzyme immunoassays (EIAs) between November 2007 and April 2008. Plasma levels of sTNFR-1, OPG, NAP-2, MCP-4 and CXCL16 were analysed by EIAs with antibodies from R\&D Systems (Minneapolis, MN, USA) according to the manufacturer's instructions. CRP was measured by EIA as described previously [24]. The intra- and inter-assay coefficients of variation were $<11 \%$ for all EIAs. The detection limits for the six markers were: CRP $0.16 \mu \mathrm{g} \cdot \mathrm{mL}^{-1}$, sTNFR-1 $7 \mathrm{pg} \cdot \mathrm{mL}^{-1}$, OPG $15 \mathrm{pg} \cdot \mathrm{mL}^{-1}, \mathrm{MCP}-4 \quad 6 \mathrm{pg} \cdot \mathrm{mL}^{-1}, \mathrm{NAP}-2 \quad 15 \mathrm{pg} \cdot \mathrm{mL}^{-1}$, and CXCL16 $5 \mathrm{pg} \cdot \mathrm{mL}^{-1}$. All individuals had plasma levels above 


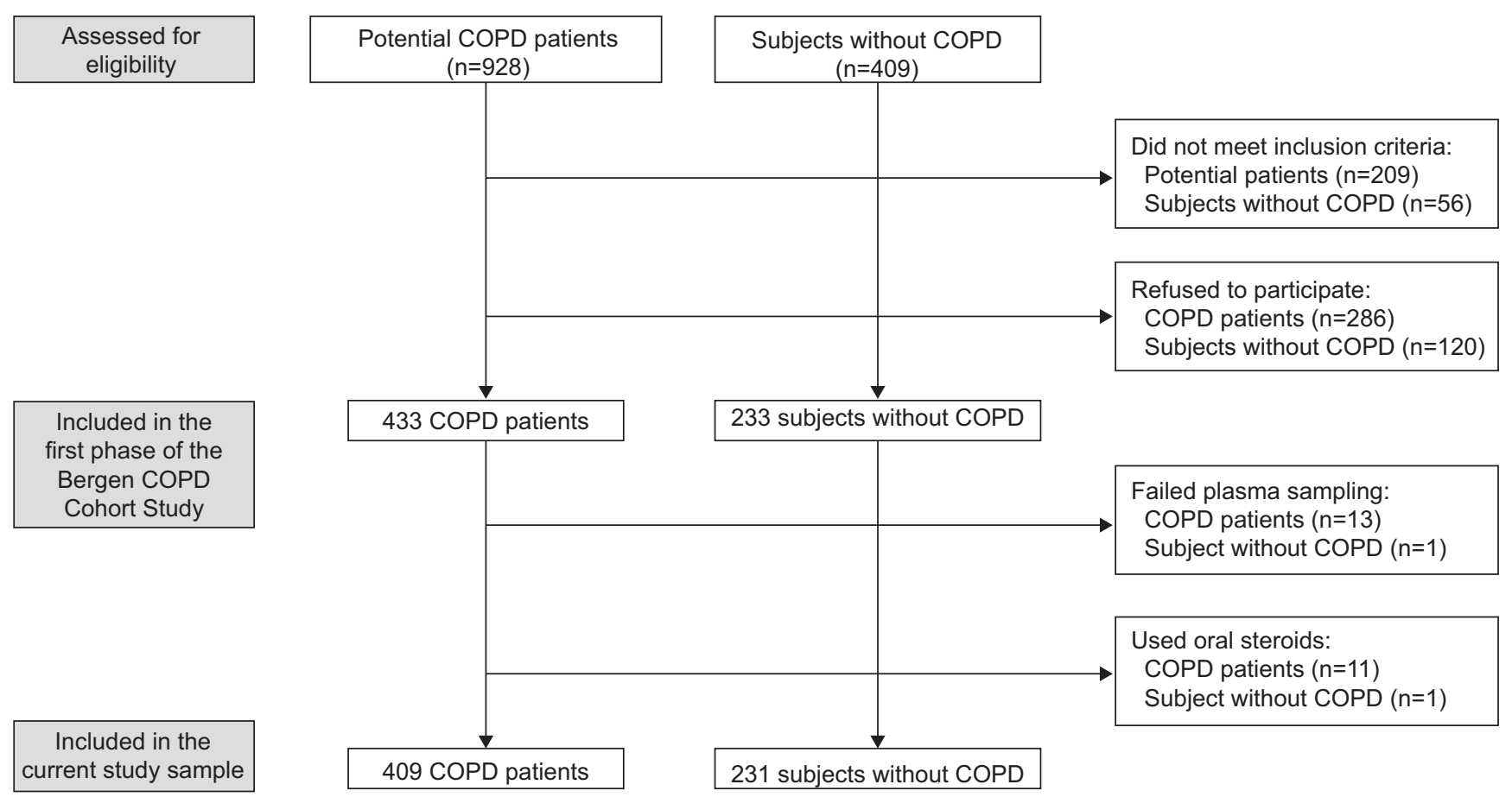

FIGURE 1. Flowchart of the selection of the study population. COPD: chronic obstructive pulmonary disease.

the detection limits of the assays for all parameters. For six subjects we ran out of plasma before all markers were examined.

\section{Statistical analyses}

For all markers except NAP-2 the distribution was not normal. Nonparametrical tests were used to examine differences in concentration of each marker between study groups. Linear regression models were used for the multivariable analyses. After the fitting of each model, the distribution of the residuals were plotted and assessed by histograms and kernel density plots. The residuals were normally distributed for all markers except CRP, where a normal distribution of the residuals was evident after $\log$ transformation.

For the models predicting the level of each of the six markers in patients and subjects without COPD, the main interest was whether study category (subjects with or without COPD) was associated with each outcome after adjustment for all possible confounders. Sex, age, body composition (FMI and FFMI) and smoking were all included in these six models as confounders. In addition, any comorbidity was considered, including comorbid heart disease, history of treatment for hypertension, history of depression of a magnitude requiring treatment, or use of platelet inhibitors. All first-order interactions between study category and the other covariables were deemed significant if the $\mathrm{p}$-value was $<0.05$.

For the linear models with COPD patients only, the main associations of interest were whether variables indicating disease severity, symptoms or significant comorbidities were related to each marker. For each model all covariables as well as sex, age, body composition, and smoking were initially included in the model. A backward stepwise procedure was then performed retaining all variables with a $\mathrm{p}$-value $>0.10$. After this procedure all excluded variables were included again one by one into the model, and retained if the p-value was $<0.10$. Whether continuous variables such as age, FMI, FFMI, and pack-yrs were to be treated as continuous or categorical variables was determined by the method of fractional polynomials for each model [25]. All analyses were computed with Stata version 10.1 (StataCorp. LP, College Station, TX, USA).

\section{RESULTS}

The study included 272 females and 368 males. Compared with the subjects without COPD, among the COPD patients there were more males, the average age was higher, and the prevalence of comorbidities was higher (table 1). Almost half the patients belonged to Global Initiative for Chronic Obstructive Lung Disease (GOLD) category II. Almost one in six COPD patients had experienced at least two or more exacerbations in the last year, and almost one in eight were hypoxaemic (table 1).

\section{Inflammatory markers in subjects with and without COPD}

The concentrations for each marker among COPD patients and subjects without COPD are shown in figure 2. Statistically significant differences between COPD patients and subjects without COPD were seen for CRP, sTNFR-1 and MCP-4. The largest difference was seen for CRP, being more than twice as high in COPD patients as subjects without COPD. For CXCL16 and NAP-2 there were no differences between COPD patients and controls in the bivariate analyses (fig. 2).

In the multivariable analyses, sTNFR-1 was no longer different between COPD patients and subjects without COPD after 
TABLE 1 Baseline characteristics by subject category

\begin{tabular}{|c|c|c|c|}
\hline & $\begin{array}{c}\text { COPD } \\
\text { subjects }\end{array}$ & $\begin{array}{l}\text { Healthy } \\
\text { subjects }\end{array}$ & p-value ${ }^{\#}$ \\
\hline Subjects $\mathrm{n}$ & 409 & 231 & \\
\hline Sex & & & 0.02 \\
\hline Female & 39.1 & 48.5 & \\
\hline Male & 60.9 & 51.5 & \\
\hline Age yrs & $63.6 \pm 6.9$ & $54.7 \pm 8.5$ & $<0.01$ \\
\hline Smoking habits & & & $<0.01^{f}$ \\
\hline Never & 0.0 & 19.5 & \\
\hline Ex & 56.7 & 10.4 & \\
\hline Current & 43.3 & 70.1 & \\
\hline Comorbid heart disease & & & $<0.01$ \\
\hline No & 79.5 & 96.1 & \\
\hline Yes & 20.5 & 3.9 & \\
\hline Medically treated hypertension & & & $<0.01$ \\
\hline No & 68.0 & 84.9 & \\
\hline Yes & 32.0 & 15.2 & \\
\hline Using regular platelet inhibitors & & & $<0.01$ \\
\hline No & 76.0 & 90.0 & \\
\hline Yes & 24.0 & 10.0 & \\
\hline $\begin{array}{l}\text { Ever had depression requiring } \\
\text { medical treatment }\end{array}$ & & & 0.02 \\
\hline No & 75.0 & 83.1 & \\
\hline Yes & 25.0 & 16.9 & \\
\hline \multicolumn{4}{|l|}{ GOLD category } \\
\hline II (FEV1 50-80) & 47.4 & 0 & \\
\hline III (FEV1 30-50) & 41.8 & 0 & \\
\hline IV (FEV1 0-30) & 10.8 & 0 & \\
\hline \multicolumn{4}{|l|}{$\begin{array}{l}\text { Experienced } \geqslant 2 \text { exacerbations } \\
\text { last year }\end{array}$} \\
\hline No & 83.4 & & \\
\hline Yes & 16.6 & & \\
\hline \multicolumn{4}{|l|}{ Hypoxaemia (resting $\left.\mathrm{Pa}_{\mathrm{a}} \mathrm{O}_{2}<8.0\right)^{\mathrm{S}}$} \\
\hline No & 87.1 & & \\
\hline Yes & 12.9 & & \\
\hline \multicolumn{4}{|l|}{ Chronic cough } \\
\hline No & 53.6 & & \\
\hline Yes & 46.4 & & \\
\hline \multicolumn{4}{|l|}{ Dyspnoea grade III } \\
\hline No & 57.1 & & \\
\hline Yes & 42.9 & & \\
\hline
\end{tabular}

Data are presented as $\%$ or mean \pm SD, unless otherwise stated. COPD: chronic obstructive pulmonary disease; GOLD: Global Initiative for Chronic Obstructive Lung Disease; FEV1: forced expiratory volume in $1 \mathrm{~s} ; \mathrm{Pa}_{1} \mathrm{O}_{2}$ : alveolar oxygen tension. ${ }^{*}$ : Chi-squared for categorical variables, unpaired t-test for continuous variables; ": either known heart failure or coronary heart disease; ${ }^{+}$. exacerbations requiring either hospitalisation or treatment with oral antibiotics or oral steroids; ${ }^{\S}$ : missing data for 38 subjects; ${ }^{f}$ : Chi-squared not including the category with no smoking.

adjustment for confounders, whereas OPG was significantly lower among COPD patients (table 2). For MCP-4, there was an interaction between sex and subject group, where a significant difference in MCP-4 was found between COPD patients and subjects without COPD only in males. Therefore, after adjustment for the confounders sex, age, body composition, smoking and possible comorbidities, a significant difference between COPD patients and subjects without COPD was seen for CRP, OPG and MCP-4 in males (table 2).

\section{Inflammatory markers in relation to characteristics of the COPD patients: bivariate analyses}

The markers CRP, sTNFR-1, OPG and MCP-4 showed differences between COPD patients and subjects without COPD in the bivariate or multivariate analyses, and were further examined among the 409 COPD patients (table 3). Mean concentration of CRP increased by exacerbation history, hypoxaemia and hypertension. Mean concentration of sTNFR-1 varied most notably by comorbid heart disease, hypertension and use of platelet inhibition. All three indices of COPD severity (GOLD category, frequent exacerbations and hypoxaemia) were associated with higher levels of OPG. In addition, higher levels of OPG were seen in patients with comorbid heart disease or hypertension (table 3 ). The only COPD disease characteristic related to mean concentration of MCP-4 was the use of inhaled steroids (table 3) and, therefore, MCP-4 was not included in further multivariate analyses.

\section{Inflammatory markers in relation to characteristics of the COPD patients: multivariate analyses}

The final multivariable regression models for CRP, sTNFR-1, and OPG among the COPD patients are shown in table 4 . The levels of sTNFR-1 decreased significantly with lower FEV1, whereas the levels of OPG increased, underscoring that these markers may reflect distinct inflammatory pathways. Having had two or more exacerbations in the previous 12 months was associated with higher levels of CRP and OPG. Hypoxaemia was insignificantly associated with all three markers after adjustment for confounders.

sTNFR-1 was strongly associated with hypertension or depression among the COPD patients, and possibly associated with CHD $(p=0.06)$. Hypertension was no longer a predictor of the level of CRP in the multivariable analysis; however, use of platelet inhibitors was. Use of platelet inhibitors was strongly related to known heart disease and could be a confounder. However, when use of platelet inhibitors was excluded from the model, and known heart disease or hypertension added, neither showed a significant relationship with CRP (data not shown).

\section{DISCUSSION}

In the present study, we have shown that COPD patients are characterised by differences in plasma levels of several inflammatory markers (i.e. CRP, OPG, sTNF-R1 and MCP-4) compared to subjects without COPD. However, after adjustment for sex, age, body composition, smoking, comorbidities and use of platelet inhibitors, only CRP and MCP-4 in males were increased, whereas OPG was decreased in COPD patients. Among the COPD patients, lower FEV1 was associated with higher OPG levels. A history of frequent exacerbations was associated with increased levels of CRP, sTNFR-1 and OPG. Finally, some of these inflammatory markers were associated with comorbidity, most notably sTNFR-1 where high levels were independently associated with hypertension and depression. These findings support a role for inflammation in COPD, potentially contributing to progression of pulmonary disease as well as comorbidity. 

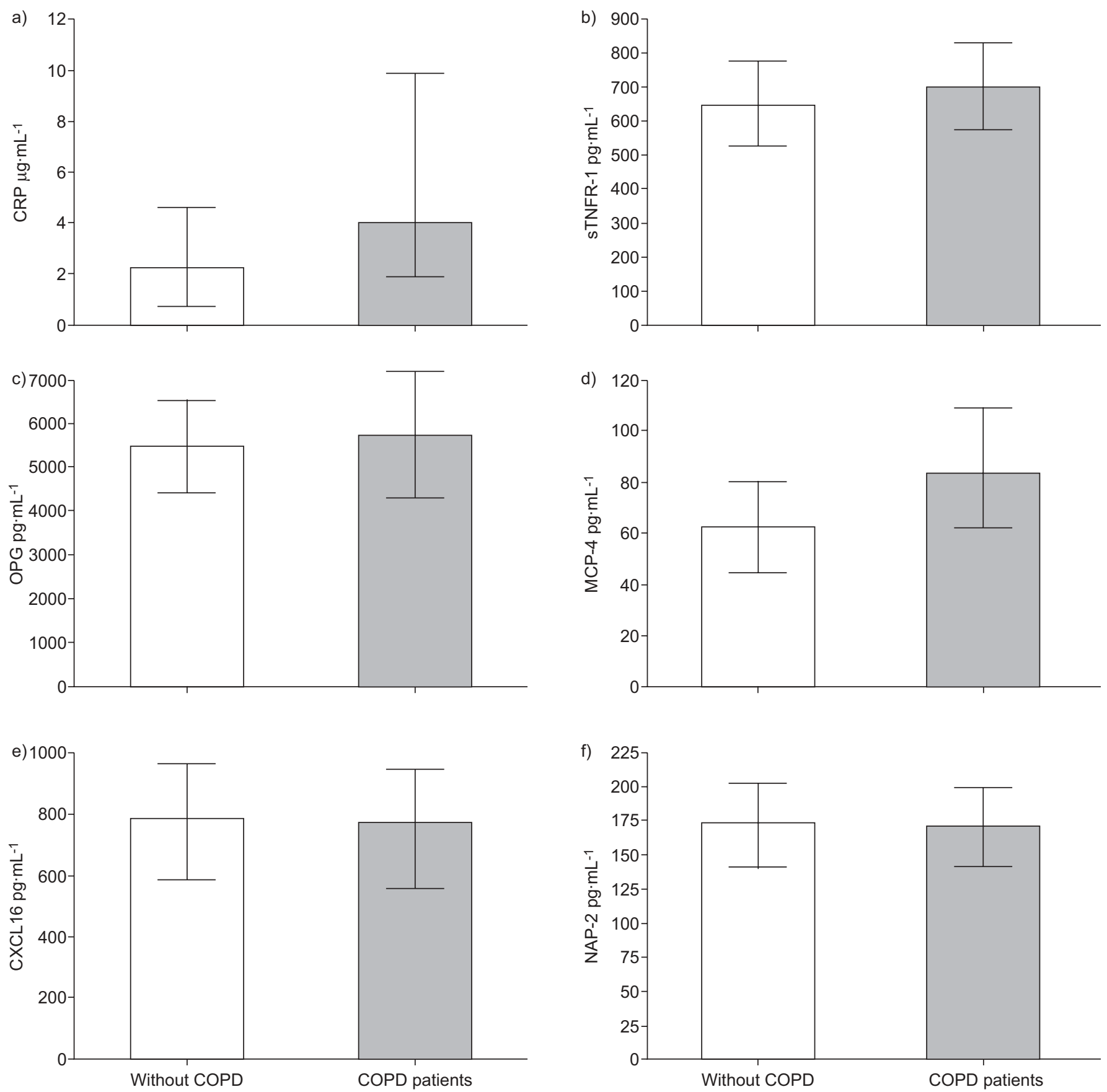

FIGURE 2. The concentration of a) C-reactive protein (CRP), b) soluble tumour necrosis factor receptor (sTNFR)-1, c) osteoprotegrin (OPG), d) monocyte chemoattractant protein (MCP)-4, e) CXCL16 and f) neutrophil activating peptide (NAP)-2 in subjects with and without chronic obstructive pulmonary disease (COPD). Data are presented as $a-e$ ) median (interquartile range) or f) mean $\pm S D$. $a, b, d$ ) $p<0.01, c) p=0.08$, e) $p=0.17$ and f) $p=0.59$.

High CRP levels were independently associated with COPD, and significantly correlated with two or more exacerbations in the previous 12 months. The finding that CRP was higher in COPD patients than in subjects without COPD is in accordance with other studies [3-7, 26]. Through its opsonising properties, CRP could play a protective role in the host defence against various microbes that are involved in exacerbations of COPD [27]. However, the leading role of CRP as an inflammatory biomarker in various disorders (e.g. CHD) is primarily based on its ability to reflect upstream inflammatory activity [28], which may also be true in COPD.

The inflammatory processes that underlie COPD are probably mediated by a multitude of cytokines and not reflected by CRP levels alone. In the present study we report raised levels of several other markers of systemic inflammation that may reflect inflammatory pathways distinct from that of CRP. Several different cell types have the capacity to secrete TNF- $\alpha$, including 


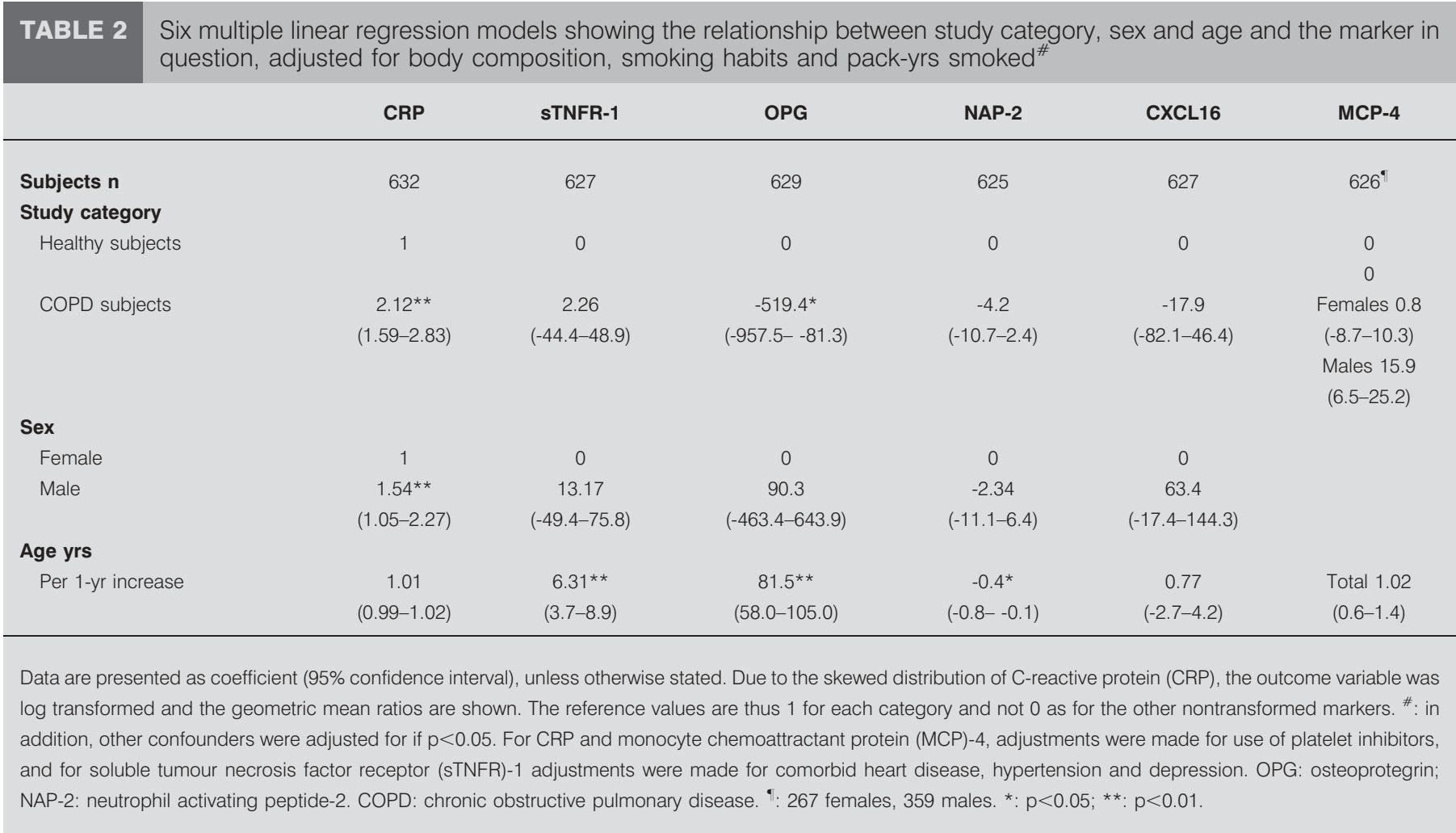

macrophages, mast cells, T-cells, epithelial cells and airway smooth muscle cells. Increased systemic TNF- $\alpha$ levels have been reported in COPD patients [9, 12, 13, 29], and increased sTNFR-1 in sputum [30]. In this study, plasma sTNFR-1 actually decreased with lower FEV1 after extensive adjustment for confounders, and increased with presence of comorbidity and/or frequent exacerbations. Patients with COPD have increased occurrence of CHD. Although the raised sTNFR-1 levels in relation to CHD may be a secondary phenomenon, increased TNF- $\alpha$ activity could also represent a pathogenic link between these inflammatory interacting disorders (i.e. CHD and COPD). Moreover, recent studies have suggested a role for persistent inflammation in depressive disorders, at least partly involving the TNF system [31]. One could speculate that TNF activity in COPD is related to specific phenotypes of patients, like patients who are prone to have frequent exacerbations, and patients with comorbid diseases, rather than related to the disease progression per se. To better understand the role of the TNF system in COPD, longitudinal studies are needed.

The OPG/RANKL/RANK axis has been shown to have pleiotropic effects on both bone metabolism [32] and the immune system [33], and was recently implicated in the development of atherosclerotic disorders [34]. To our knowledge, the present study is the first report of dysregulated OPG levels in COPD. Plasma OPG was significantly lower in COPD patients after adjustment for confounders. In contrast, raised OPG levels were most closely related to disease severity, showing a significant association with low FEV1 and disease exacerbations in the previous 12 months. The reason for this apparent inconsistency is unclear, but could reflect the involvement of the OPG/RANKL/RANK axis in more severe disease compared with mild disease, and could also possibly reflect the ability of OPG to induce matrix degradation on its own at high concentrations [35].

Chemokines may play an important role in the recruitment of inflammatory cells from the circulation to the airways in both asthma and COPD [36]. While we found no differences in plasma levels of NAP-2 and CXCL16 between COPD patients and controls, male COPD patients showed enhanced MCP-4 levels even in the multivariate analyses. MCP-4 is implicated in the recruitment of eosinophils, monocytes, and T-cells in diseases of mucosal inflammation, including asthma. Elevated MCP-4 levels have been found in patients with asthma, with the highest levels recorded during acute asthma exacerbations [37]. Although the cytokine profile may differ between asthma and COPD, our finding suggests that MCP-4 could also be linked to COPD, at least in males.

Several mechanisms may contribute to the enhanced systemic inflammation in COPD, such as oxidative stress, hypoxia and interactions between various microbes and toll-like receptors (TLRs) within the airways and pulmonary tissue [38-40]. The association between some of the inflammatory mediators and disease exacerbations in the previous 12 months could support the involvement of TLR-related mechanisms. Whatever the mechanisms, low-grade inflammation in COPD patients could promote further inflammatory responses within pulmonary tissue, representing a self-perpetuating inflammatory loop contributing to disease progression in COPD.

The strength of the current study is its large sample size that allows for analyses on important clinical subgroups of COPD 
TABLE 3 Concentration of four inflammatory markers in chronic obstructive pulmonary disease patients

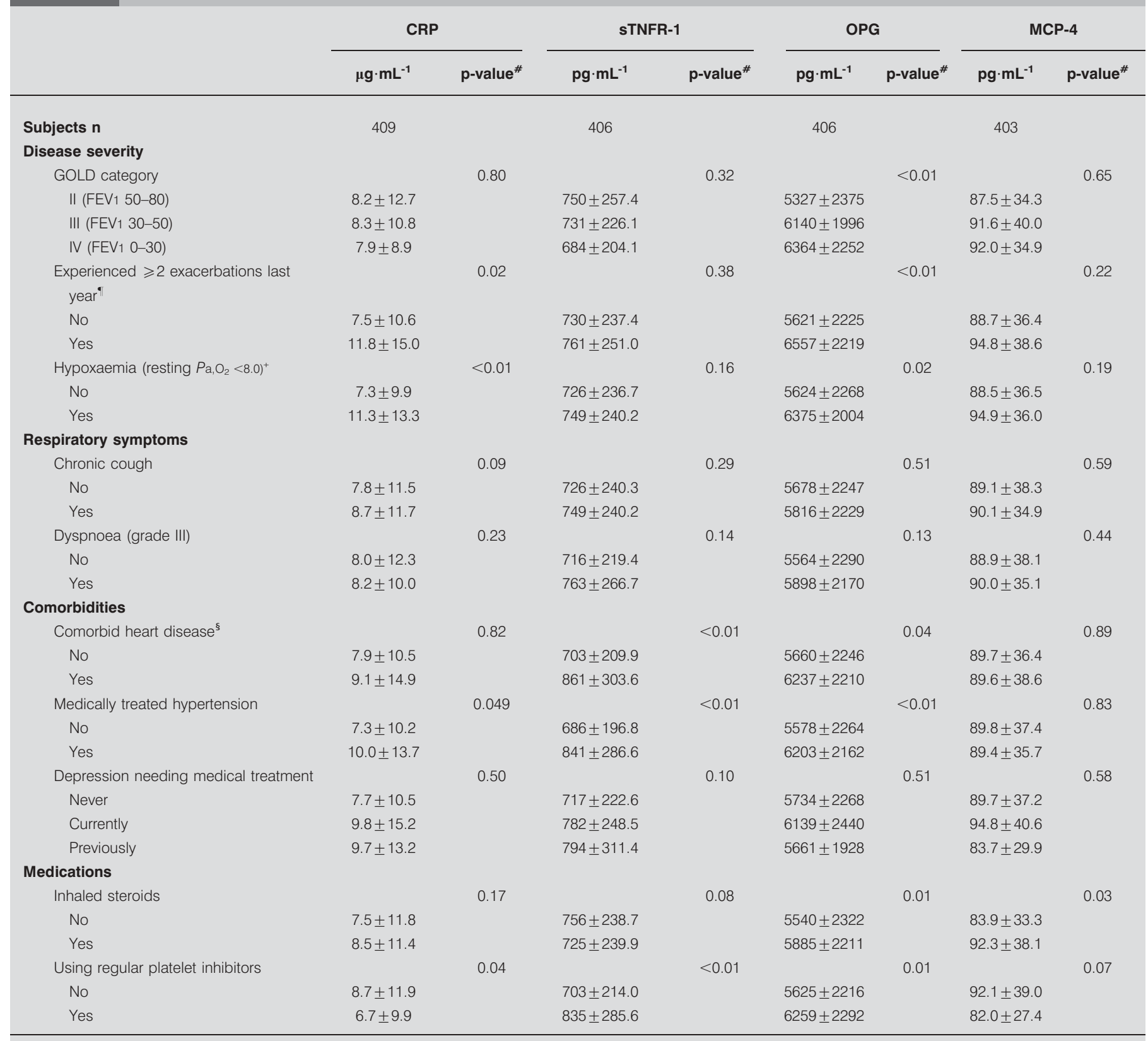

Data are presented as mean $\pm \mathrm{SD}$, unless otherwise stated. CRP: C-reactive protein; sTNFR-1: soluble tumour necrosis factor receptor-1; OPG: osteoprotegrin; MCP-4: monocyte chemoattractant protein-4; GOLD: Global Initiative for Chronic Obstructive Lung Disease; FEV1: forced expiratory volume in $1 \mathrm{~s} ; P_{\mathrm{a}} \mathrm{O}_{2}$ : alveolar oxygen tension. ${ }^{*}$ : Wilcoxon rank sum test used for all variables, except FEV1 and depression, where the Kruskal-Wallis test was used; ${ }^{\circ}$ : exacerbations requiring treatment either with oral antibiotics or oral steroids or hospitalisation; ${ }^{+}$: missing data for 38 subjects; ${ }^{\varsigma}$ : either known heart failure or coronary heart disease.

patients. However, there are some methodological considerations in relation to the current study. There were significant differences between patients and subjects without COPD for almost all variables examined. This is partly reflects that there was no active matching between patients and subjects without COPD during inclusion, and partly that some differences are probably manifestations of the disease. To find perfect controls for a patient cohort with a complex disease such as COPD is difficult, and we preferred an unmatched group from a previous randomly selected general population sample. With this strategy it is imperative to fully adjust for the possible confounding factors. In the current study, there were significantly fewer ex-smokers among subjects without COPD than among the COPD patients. Although, smoking was adjusted for in the multivariable models, residual confounding by smoking cannot be completely ruled out. Our results underscore the need for large study populations, being able to correct for multiple confounders, before making firm 


\begin{tabular}{|c|c|c|c|c|}
\hline \multirow[t]{2}{*}{ TABLE 4} & \multicolumn{4}{|c|}{$\begin{array}{l}\text { Multiple linear regression of the level of three } \\
\text { inflammatory markers in chronic obstructive } \\
\text { pulmonary disease }\end{array}$} \\
\hline & & CRP & STNFR-1 & OPG \\
\hline \multicolumn{2}{|c|}{$\begin{array}{l}\text { Subjects } n \\
\text { GOLD category }\end{array}$} & 404 & 401 & 402 \\
\hline \multicolumn{2}{|c|}{ II (FEV1 50-80) } & & 0 & 0 \\
\hline \multicolumn{2}{|c|}{ III (FEV $130-50)$} & & $\begin{array}{c}-43.73 \\
(-90.5-3.1)\end{array}$ & $\begin{array}{c}530.5^{\star} \\
(76.9-984.0)\end{array}$ \\
\hline \multicolumn{2}{|c|}{ IV (FEV1 0-30) } & & $\begin{array}{c}-91.45^{\star} \\
(-167.9--15.0)\end{array}$ & $\begin{array}{c}536.2 \\
(-196.3-1268.8)\end{array}$ \\
\hline \multicolumn{5}{|c|}{$\begin{array}{l}\text { Experienced } \geqslant 2 \text { exacerbations } \\
\text { last year }\end{array}$} \\
\hline \multicolumn{2}{|l|}{ No } & 1 & 0 & 0 \\
\hline \multicolumn{2}{|l|}{ Yes } & $\begin{array}{c}1.44^{*} \\
(1.02-2.04)\end{array}$ & $\begin{array}{c}53.41 \\
(-7.2-114.0)\end{array}$ & $\begin{array}{c}652.6^{\star} \\
(69.8-1235.3)\end{array}$ \\
\hline \multicolumn{5}{|c|}{ Chronic cough } \\
\hline \multicolumn{2}{|l|}{ No } & 1 & & \\
\hline Yes & & $\begin{array}{c}0.67^{\star} \\
(0.49-0.91)\end{array}$ & & \\
\hline \multicolumn{5}{|c|}{ Comorbid heart disease $^{\#}$} \\
\hline \multicolumn{2}{|l|}{ No } & & 0 & \\
\hline Yes & & & $\begin{array}{c}57.49 \\
(-3.2-118.2)\end{array}$ & \\
\hline \multicolumn{5}{|c|}{ Medically treated hypertension } \\
\hline \multicolumn{2}{|l|}{ No } & & 0 & \\
\hline Yes & & & $\begin{array}{c}98.8^{*} \\
(46.9-150.7)\end{array}$ & \\
\hline \multicolumn{5}{|c|}{$\begin{array}{l}\text { Depression needing medical } \\
\text { treatment }\end{array}$} \\
\hline \multicolumn{2}{|l|}{ Never } & & 0 & \\
\hline \multicolumn{2}{|l|}{ Currently } & & $\begin{array}{c}81.53^{*} \\
(16.6-146.5)\end{array}$ & \\
\hline \multicolumn{2}{|l|}{ Previously } & & $\begin{array}{c}69.46^{*} \\
(3.7-135.3)\end{array}$ & \\
\hline
\end{tabular}

Data are presented as coefficient (95\% confidence interval), unless otherwise stated. Due to the skewed distribution of C-reactive protein (CRP), the outcome variable was log transformed, and the geometric mean ratios are shown. The reference values are thus 1 for each category and not 0 as for the other nontransformed markers. All models include adjustment for sex, age, body composition, smoking habits and use of inhaled steroids and/or platelet inhibitors. STNFR-1: soluble tumour necrosis factor receptor-1; OPG: osteoprotegrin; GOLD: Global Initiative for Chronic Obstructive Lung Disease; FEV1: forced expiratory volume in $1 \mathrm{~s} .{ }^{\#}$ : either known heart failure or coronary heart disease. *: $p<0.05$

conclusions. Moreover, this is a cross-sectional study, and inference of cause and effect is not possible. Future studies should include longitudinal follow-up data.

In conclusion, despite the limitations mentioned, the present study reinforces the view that systemic inflammation is an important phenotypic feature of COPD. Future prospective studies should investigate if these markers will give important prognostic information in relation to disease progression and severity in COPD.

\section{SUPPORT STATEMENT}

The study was funded by grants from The Foundation for Respiratory Research, University of Bergen, Bergen, Norway and by grants from the Center for Clinical Research, Haukeland University Hospital, Bergen, Norway.

\section{STATEMENT OF INTEREST}

None declared.

\section{REFERENCES}

1 O'Donnell R, Breen D, Wilson S, et al. Inflammatory cells in the airways in COPD. Thorax 2006; 61: 448-454.

2 Hogg JC, Chu F, Utokaparch S, et al. The nature of small-airway obstruction in chronic obstructive pulmonary disease. $N$ Engl J Med 2004; 350: 2645-2653.

3 Broekhuizen R, Grimble RF, Howell WM, et al. Pulmonary cachexia, systemic inflammatory profile, and the interleukin $1 \beta$ 511 single nucleotide polymorphism. Am J Clin Nutr 2005; 82: 1059-1064.

4 Mannino DM, Ford ES, Redd SC. Obstructive and restrictive lung disease and markers of inflammation: data from the Third National Health and Nutrition Examination. Am J Med 2003; 114 758-762.

5 Pinto-Plata VM, Mullerova H, Toso JF, et al. C-reactive protein in patients with COPD, control smokers and non-smokers. Thorax 2006; 61: 23-28.

6 Yanbaeva DG, Dentener MA, Spruit MA, et al. IL6 and CRP haplotypes are associated with COPD risk and systemic inflammation: a case-control study. BMC Med Genet 2009; 10: 23.

7 Yende S, Waterer GW, Tolley EA, et al. Inflammatory markers are associated with ventilatory limitation and muscle dysfunction in obstructive lung disease in well functioning elderly subjects. Thorax 2006; 61: 10-16.

8 Dahl M, Tybjaerg-Hansen A, Vestbo J, et al. Elevated plasma fibrinogen associated with reduced pulmonary function and increased risk of chronic obstructive pulmonary disease. Am J Respir Crit Care Med 2001; 164: 1008-1011.

9 Bolton CE, Ionescu AA, Shiels KM, et al. Associated loss of fat-free mass and bone mineral density in chronic obstructive pulmonary disease. Am J Respir Crit Care Med 2004; 170: 1286-1293.

10 Piehl-Aulin K, Jones I, Lindvall B, et al. Increased serum inflammatory markers in the absence of clinical and skeletal muscle inflammation in patients with chronic obstructive pulmonary disease. Respiration 2009; 78: 191-196.

11 Schols AM, Buurman WA, Staal van den Brekel AJ, et al. Evidence for a relation between metabolic derangements and increased levels of inflammatory mediators in a subgroup of patients with chronic obstructive pulmonary disease. Thorax 1996; 51: 819-824.

12 Itoh $\mathrm{T}$, Nagaya N, Yoshikawa $\mathrm{M}$, et al. Elevated plasma ghrelin level in underweight patients with chronic obstructive pulmonary disease. Am J Respir Crit Care Med 2004; 170: 879-882.

13 Takabatake N, Nakamura H, Abe S, et al. Circulating leptin in patients with chronic obstructive pulmonary disease. Am J Respir Crit Care Med 1999; 159: 1215-1219.

14 Shin KC, Chung JH, Lee KH. Effects of TNF- $\alpha$ and leptin on weight loss in patients with stable chronic obstructive pulmonary disease. Korean J Intern Med 2007; 22: 249-255.

15 Wagner PD. Possible mechanisms underlying the development of cachexia in COPD. Eur Respir J 2008; 31: 492-501.

16 Schane RE, Woodruff PG, Dinno A, et al. Prevalence and risk factors for depressive symptoms in persons with chronic obstructive pulmonary disease. J Gen Intern Med 2008; 23: 1757-1762.

17 Soriano JB, Visick GT, Muellerova H, et al. Patterns of comorbidities in newly diagnosed COPD and asthma in primary care. Chest 2005; 128: 2099-2107. 
18 Dempsey PW, Doyle SE, He JQ, et al. The signaling adaptors and pathways activated by TNF superfamily. Cytokine Growth Factor Rev 2003; 14: 193-209.

19 Eagan T, Eide G, Gulsvik A, et al. Nonresponse in a community cohort study. Predictors and consequences for exposure-disease associations. J Clin Epidemiol 2002; 55: 775-781.

20 Johannessen A, Lehmann S, Omenaas ER, et al. Post-bronchodilator spirometry reference values in adults and implications for disease management. Am J Respir Crit Care Med 2006; 173: 1316-1325.

21 Bakke P, Gulsvik A, Lilleng P, et al. Postal survey on airborne occupational exposure and respiratory disorders in Norway: causes and consequences of non-response. J Epidemiol Community Health 1990; 44: 316-320.

22 Eagan TM, Bakke PS, Eide GE, et al. Incidence of asthma and respiratory symptoms by sex, age and smoking in a community study. Eur Respir J 2002; 19: 599-605.

23 Miller MR, Hankinson J, Brusasco V, et al. Standardisation of spirometry. Eur Respir J 2005; 26: 319-338.

$24 \mathrm{Wu} \mathrm{TL}$, Tsao KC, Chang CP, et al. Development of ELISA on microplate for serum C-reactive protein and establishment of agedependent normal reference range. Clin Chim Acta 2002; 322: 163-168.

25 Royston P, Ambler G, Sauerbrei W. The use of fractional polynomials to model continuous risk variables in epidemiology. Int J Epidemiol 1999; 28: 964-974.

26 Gan WQ, Man SF, Senthilselvan A, et al. Association between chronic obstructive pulmonary disease and systemic inflammation: a systematic review and a meta-analysis. Thorax 2004; 59: 574-580.

27 Sethi S, Maloney J, Grove L, et al. Airway inflammation and bronchial bacterial colonization in chronic obstructive pulmonary disease. Am J Respir Crit Care Med 2006; 173: 991-998.

28 Aukrust P, Halvorsen B, Yndestad A, et al. Chemokines and cardiovascular risk. Arterioscler Thromb Vasc Biol 2008; 28: 1909-1919.
29 Yasuda N, Gotoh K, Minatoguchi S, et al. An increase of soluble Fas, an inhibitor of apoptosis, associated with progression of COPD. Respir Med 1998; 92: 993-999.

30 Vernooy JH, Kucukaycan M, Jacobs JA, et al. Local and systemic inflammation in patients with chronic obstructive pulmonary disease: soluble tumor necrosis factor receptors are increased in sputum. Am J Respir Crit Care Med 2002; 166: 1218-1224.

31 Raison CL, Capuron L, Miller AH. Cytokines sing the blues: inflammation and the pathogenesis of depression. Trends Immunol 2006; 27: 24-31.

32 Horowitz MC, Xi Y, Wilson K, et al. Control of osteoclastogenesis and bone resorption by members of the TNF family of receptors and ligands. Cytokine Growth Factor Rev 2001; 12: 9-18.

33 Fouque-Aubert A, Chapurlat R. Influence of RANKL inhibition on immune system in the treatment of bone diseases. Joint Bone Spine 2008; 75: 5-10.

34 Abedin M, Omland T, Ueland T, et al. Relation of osteoprotegerin to coronary calcium and aortic plaque (from the Dallas Heart Study). Am J Cardiol 2007; 99: 513-518.

35 Sandberg WJ, Yndestad A, Oie E, et al. Enhanced T-cell expression of RANK ligand in acute coronary syndrome: possible role in plaque destabilization. Arterioscler Thromb Vasc Biol 2006; 26: 857-863.

36 Barnes PJ. The cytokine network in asthma and chronic obstructive pulmonary disease. J Clin Invest 2008; 118: 3546-3556.

37 Kalayci O, Sonna LA, Woodruff PG, et al. Monocyte chemotactic protein-4 (MCP-4; CCL-13): a biomarker of asthma. J Asthma 2004; 41: 27-33.

38 Langen RC, Korn SH, Wouters EF. ROS in the local and systemic pathogenesis of COPD. Free Radic Biol Med 2003; 35: 226-235.

39 Sarir H, Henricks PA, van Houwelingen AH, et al. Cells, mediators and Toll-like receptors in COPD. Eur J Pharmacol 2008; 585: 346-353.

40 Tuder RM, Yun JH, Bhunia A, et al. Hypoxia and chronic lung disease. J Mol Med 2007; 85: 1317-1324. 